\title{
A Novel Waste Plastics Firing System Based on the Melting/Gasification Characteristics
}

\author{
Joon Ahn ${ }^{1}$, Hyouck Ju Kim ${ }^{2}$ \\ ${ }^{1}$ School of Mechanical Engineering, Kookmin University, \\ Seoul, Korea \\ jahn@kookmin.ac.kr \\ ${ }^{2}$ Korea Institute of Energy Research \\ Daejeon, Korea \\ hjkim@kier.re.kr
}

\begin{abstract}
We have devised a novel combustion firing system for waste plastics, which are mainly composed of low-density polyethylene or polypropylene. The system includes a pre-combustor, which gasifies the plastics. To design the pre-combustor, we studied the melting/gasification characteristics of plastic pellets produced as fuel for the system. The pellets were melted down to an oval shape from the initial cylindrical shape at various temperatures, and firing was observed at a high temperature of $900{ }^{\circ} \mathrm{C}$. The novel burner has been designed as a boiler system. The system works well within the range from $45 \%$ to $100 \%$ of the load and emits exhaust gas in compliance with pollutant regulations
\end{abstract}

Keywords: Waste plastics, Burner, Boiler

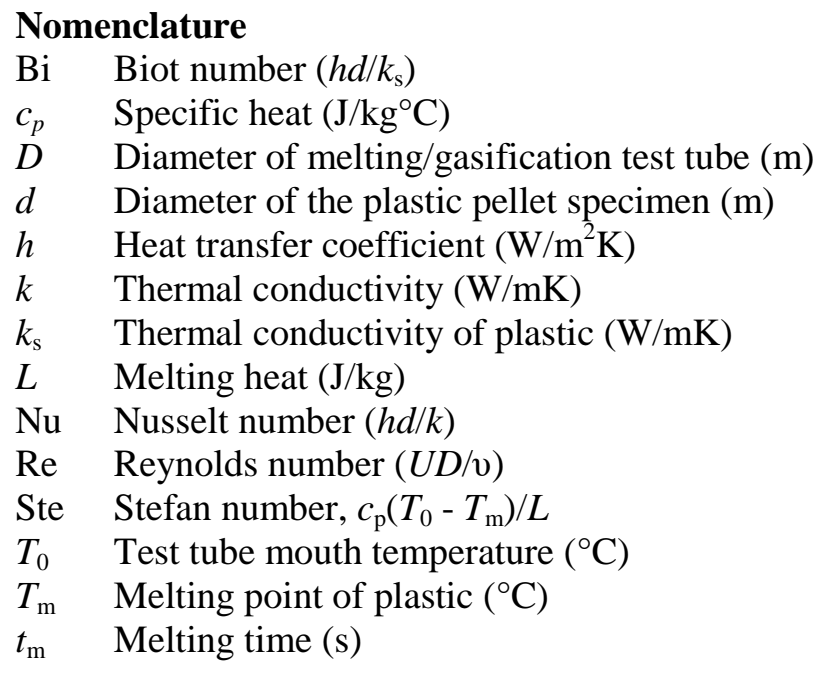

\section{Greek Alphabet}

$\begin{array}{ll}\alpha & \text { Thermal diffusion coefficient }\left(\mathrm{m}^{2} / \mathrm{s}\right) \\ \delta_{\mathrm{T}} & \text { Thickness of thermal boundary layer (m) } \\ v & \text { Coefficient of kinematic viscosity }\left(\mathrm{m}^{2} / \mathrm{s}\right)\end{array}$

\section{Introduction}

Korea ranks as the 5th largest plastic producer in the world, and more than 3 million tons of waste plastic are generated every year. Among this waste, about $60 \%$ from domestic sources is buried and the recycling rate for all plastics is as low as $18.2 \%$ [1]. Because waste plastic has a high calorific value, the recycling rate could potentially be increased greatly if that plastic was utilized as fuel, but this is not done frequently in practice because plastics undergo complex 
combustion processes such as melting, decomposition, and gasification, which are difficult to control, and some types of plastics generate harmful gases when burned [2]. The problem whereby it is difficult to control the combustion of waste plastic can be solved through pre-processing procedures. If waste plastics are crushed and mixed with other combustible materials and fabricated into RDF (refuse derived fuel), a uniform calorific value can be obtained and the fuel can be used in grate-type burners as it does not flow down during the combustion process. However, because harmful gas is generated during the combustion process, post-processing equipment is typically required to comply with exhaust gas standards. Thermally decomposing waste plastics into the form of a gas or a liquid by using another pre-processing method can alleviate some of the above mentioned problems. For example, the fuel obtained through thermal decomposition can be utilized like an existing gas or liquid fuel and the amount of pollutants generated during the combustion process is reduced. However, additional energy is required for the thermal decomposition process.

In this study, we devised a novel combustion firing system for waste plastics and tested the system on plastics composed of polyethylene (PE) and polypropylene (PP); this fuel type was used so that the system could be operated with no large-scale post-processing equipment for the reduction of harmful gases. To secure the combustion stability of this fuel, a burner equipped with a pre-combustor that can thermally decompose the fuel into gas was devised, and to design the pre-combustor, the melting/gasification characteristics that are dependent on the size of the plastic pellets and the ambient temperature were analyzed. Finally, after the newly developed combustor was installed in the boiler system, the characteristics of the flame in the system and the operation characteristics depending on the load were verified and an ingredient analysis of the exhaust gas was carried out to check whether the air pollutants conform to the allowable emission standards.

\section{Experiment Setup and Methods}

\subsection{Melting/Gasification Characteristic Test for Plastic Pellets}

The experimental setup was organized as shown in Fig. 1(b), and the plastic pellets shown in Fig. 1(a) were heated up to $900^{\circ} \mathrm{C}$ for the experimental study of the melting and gasification characteristics of the plastic pellets. The experimental conditions are given in Table 1 . To simulate a pre-combustor where thermal decomposition takes place in a low oxygen atmosphere, the specimen was heated up with burning gas. For the fuel used for heating, liquid natural gas (LNG) was supplied at a rate of $0.72 \mathrm{Nm}^{3} / \mathrm{h}$.

Table 1: Test conditions.

\begin{tabular}{|l|l|}
\hline $\operatorname{Re}\left(=u_{\mathrm{z}} D / \mathrm{n}\right)$ & $1,000-5,000$ \\
\hline $\operatorname{Re}_{\mathrm{d}}\left(=u_{\mathrm{z}} d / \mathrm{n}\right)$ & $70-1,500$ \\
\hline $\operatorname{Pe}\left(=u_{\mathrm{z}} D / \mathrm{a}\right)$ & 1,000 \\
\hline $\mathrm{Nu}(=h d / k)$ & $10-50$ \\
\hline $\operatorname{Bi}\left(=h d / k_{\mathrm{s}}\right)$ & $7-30$ \\
\hline $\mathrm{Ste}\left(=c_{\mathrm{p}}\left(T_{\mathrm{m}}-T_{0}\right) / L\right)$ & $5.7-17.6$ \\
\hline
\end{tabular}

The high temperature air obtained through combustion was supplied to the experimental area after being adjusted to fit the experimental conditions. The experimental area was produced in a quartz tube, and a piece of honeycomb was installed at the mouth so that there would be a uniform speed distribution. The temperature of the gas supplied to the test tube was adjusted within the range of 500 to $900^{\circ} \mathrm{C}$, which is the range at which the PE and PP thermally decompose. Then, the melting process of specimens with a size of 5 to $40 \mathrm{~mm}$ was recorded and the results were analyzed.

\subsection{Combustion Experiment for the Waste Plastic Pellet Boiler}

The combustor was designed and produced on the basis of the melting/gasification characteristics of waste plastics, and the experimental setup for verification was constructed by mounting the equipment on a boiler system as shown in Fig. 2(a). Pellets sold in the market for resource recycling (Fig. 2(b)) were used as the fuel, and the material properties of the 
pellets are shown in Table 2. A uniform amount of fuel was supplied to the combustor by installing a sensor on the hopper and controlling the automatic transfer device connected to the fan.

(a)
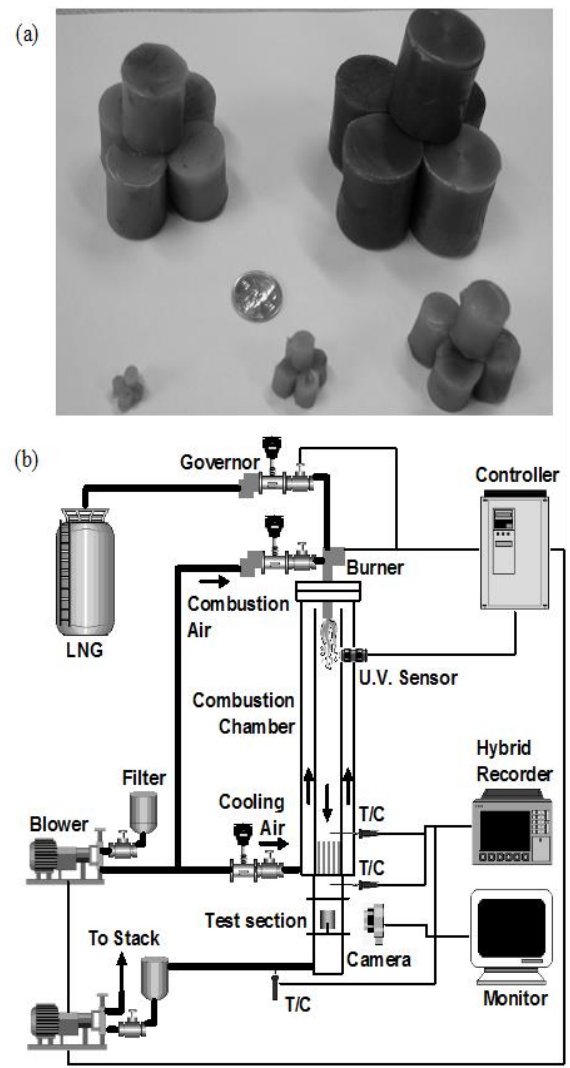

Fig. 1 Details of the melting/gasification experiment for plastic pellet samples.

(a) Plastic pellet samples; (b) schematic diagram of the experimental setup.

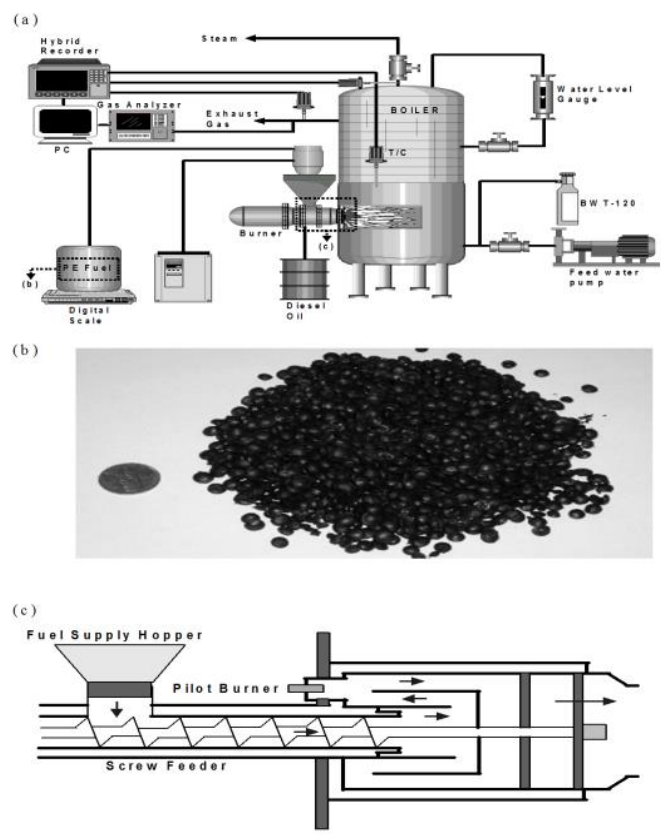

Fig. 2 Boiler system utilizing the novel waste plastics burner.

(a) Schematic diagram of the system; (b) plastic pellets used as the fuel; and (c) cross-section of the novel combustor. 
A screw feeder was used in between the hopper and the thermal decomposition space, as shown in Fig. 2(c), to prevent the melted plastic from adhering to the equipment and to ensure a fixed amount of plastic supply. Because the thermal decomposition speed of PE and PP is slow [3], the volume of the combustor was reduced and, at the same time, sufficient thermal decomposition time was secured by letting the fuel go through multiple paths as shown in Fig. 2(c); these parameters were set according to the results of the melting characteristic experiments for the fuel.

The boiler onto which the combustor was installed was a vertical type and a conduit type, and the combustion room was kept separated from the boiler part to ensure easy replacement of the combustor. The capacity of the system was $400,000 \mathrm{kcal} / \mathrm{h}$, and the design pressure was $10 \mathrm{~kg} / \mathrm{cm}^{2}$. In this study, the characteristics of combustion and exhaust gas were measured while changing the combustion load and the excess oxygen concentration of the boiler. First, the qualitative characteristics of the flame were observed by installing a camera on the observation window. The temperatures inside the boiler and of the exhaust gas were measured by using k-type thermocouples, and the ingredients of the exhaust gas were measured in real time with a gas analyzer. Emission components that could not be measured by using the universal gas analyzer, such as dioxin and heavy metals, were collected from the exhaust gas and samples were sent to a specialized analytical laboratory for analysis.

Table 2: Composition (wt $\%$ ) of the waste plastics.

\begin{tabular}{|c|c|c|c|}
\hline \multicolumn{4}{|c|}{ Element } \\
\hline $\mathrm{C}$ & $\mathrm{H}$ & $\mathrm{N}$ & $\mathrm{S}$ \\
\hline 84.13 & 15.80 & 0.01 & 0.06 \\
\hline \multicolumn{4}{|c|}{ Heating value: $10,780 \mathrm{kcal} / \mathrm{kg}$} \\
\hline
\end{tabular}

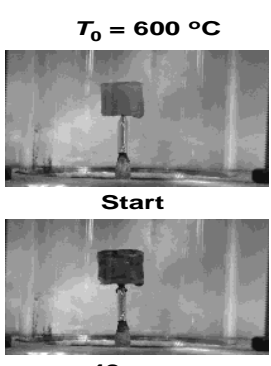

43 sec

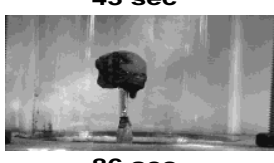

$86 \mathrm{sec}$

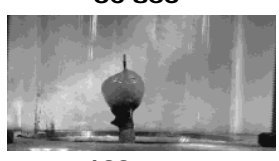

$129 \mathrm{sec}$

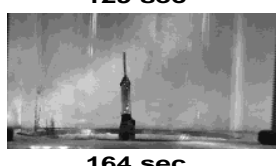

164 sec

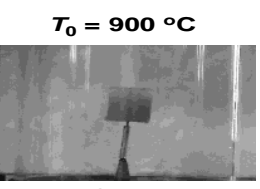

Start
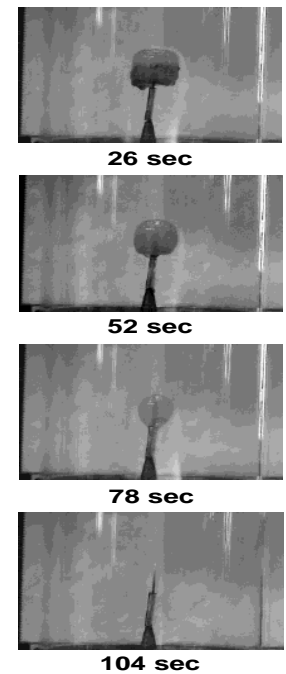

Fig. 3: Melting process for the LDPE pellets with diameters of $15 \mathrm{~mm}$.

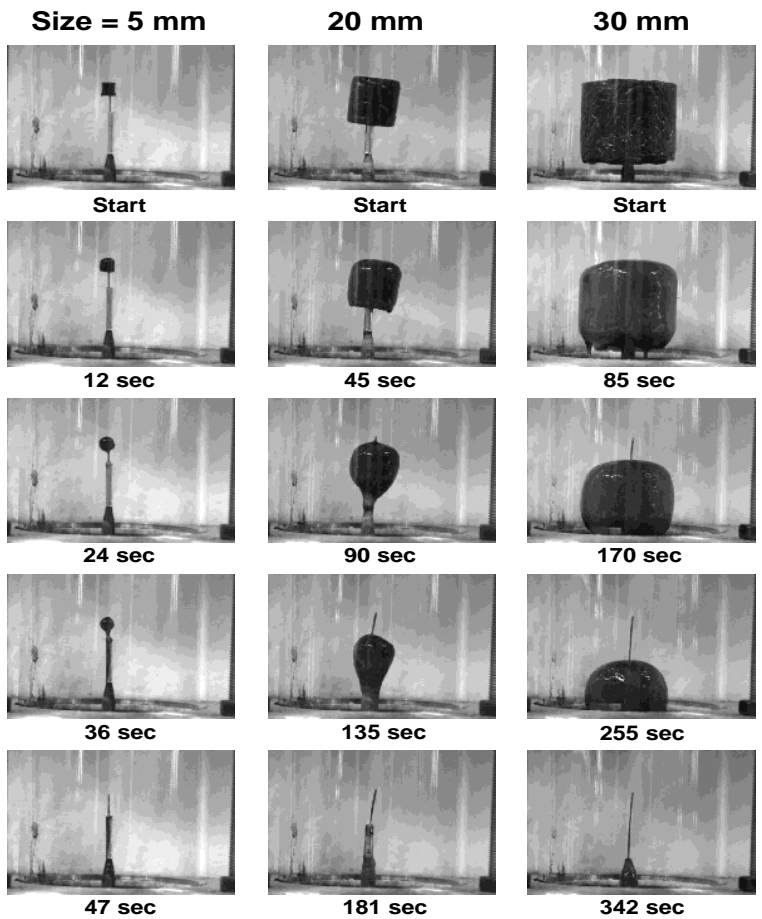

Fig. 4: Melting process for the PP pellets at $700^{\circ} \mathrm{C}$. 


\section{Results and Discussion}

\subsection{Melting/Gasification Characteristics of Plastic Pellets}

When we examined the melting process of the plastic samples at temperatures between 500 to $900^{\circ} \mathrm{C}$, the thermal decomposition temperature range for the plastics (Fig. 3), we found that only melting took place at the low temperature $\left(600^{\circ} \mathrm{C}\right)$, while a flame was also observed at the high temperature $\left(900^{\circ} \mathrm{C}\right)$. In both cases, a sample with the size of $15 \mathrm{~mm}$ starts melting from the upper edge of the specimen and is changed into an elliptical form by the surface tension as the melting advances; eventually, it changes into an elongated form in the direction of gravity because of the decrease in viscosity and the effect of gravity. When ignition takes place (Fig. 3(b)), flames form below the specimen as the movement in the flow direction is stronger than the buoyancy. When we investigated the effect of sample size (Fig. 4), we found that the smaller sized samples melted quicker than the larger samples, and all samples showed similar shape progressions, e.g., from spherical forms to elongated forms during melting.

The melting time, which depends on the size of the plastic pellets, can be predicted from the thermal equilibrium. The heat transferred from outside the pellets establishes equilibrium with the melting heat as shown in Eq. (1):

$$
K \frac{\Delta \mathrm{T}}{\delta \mathrm{T}} d^{2} \sim L \frac{\rho d^{3}}{t_{m}}
$$

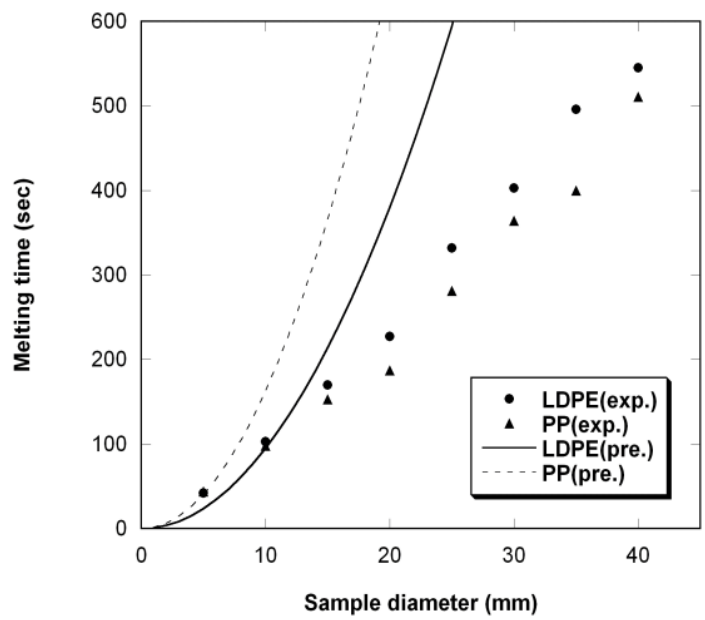

Fig. 5: Melting time according to the sample size at the temperature of $600^{\circ} \mathrm{C}$.

In Eq. (1), the thickness of the thermal boundary layer $\left(\delta_{\mathrm{T}}\right)$ was estimated by using the Whitaker relational expression [4], and the data are presented in Fig. 5 along with the results of the experiment. Though the results for the predictions were similar to the experimental data when the diameter of the sample was within $15 \mathrm{~mm}$, the melting speed quickened more than predicted as the specimens transformed away from spherical shapes possibly because of changes in thermal processes initiated by changes in the chemical bonds or gasification reactions. In the case of PP, other thermal processes that accompanied the melting may have had a bigger effect than those acting on low-density PE (LDPE).

\subsection{Burning Characteristics of Waste Plastic Pellets in a Boiler}

Photograph of the flames generated by the combustor developed in this study are presented in Fig. 6. As the thermal decomposition is well carried out in the thermal decomposition space of the combustor, the form of the flame shows similar characteristics to those of a non-premixed flame. It was observed that as the load rate increased, the amount of fuel burnt increased and the flames were larger. As the composition of the fuel is similar to that of naphtha (Table 2), the color of the flame was dark yellow similar to that of flames generated when heavy oil is burnt.

The performance of the combustor was evaluated by using the characteristics of the exhaust gas emitted after the plastic fuel was burnt in the combustor of the boiler. In this study, the burning characteristics were adjusted by changing the load rate of the combustor to $45 \%, 80 \%$, and $100 \%$. The concentration of CO (Fig. 7(a)) showed a superior emission 
characteristic of $90 \mathrm{ppm}$ or less under wide ranges of conditions, i.e., across load rates from $45 \%$ to $100 \%$ and oxygen concentrations from $3 \%$ to $15 \%$. In the case of load rates of $80 \%$ and $100 \%$, the amount of CO rapidly decreased as the oxygen concentration increased, and if the oxygen concentration was $7 \%$ or higher, the $\mathrm{CO}$ showed a trend that converged almost to zero. When the load rate was $45 \%$, though it already showed characteristics close to perfect combustion if the excess oxygen concentration was $3 \%$, the $\mathrm{CO}$ concentration showed a property of not being reduced as an effect was generated whereby $\mathrm{CO}$ increased as the temperature of the flame was cooled down when the oxygen concentration was increased.

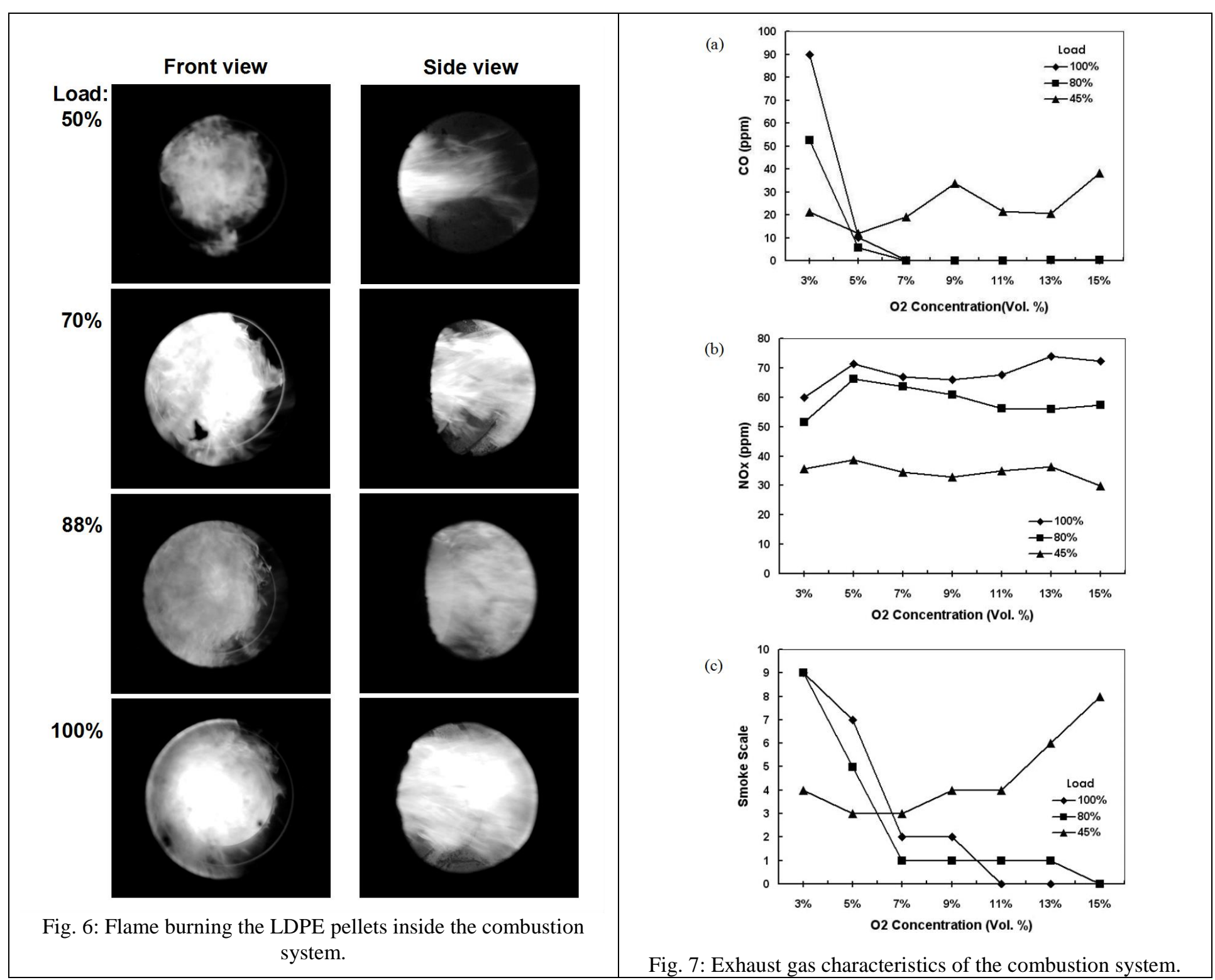

In the case of nitrogenous compounds (NOx) (Fig. 7(b)), as the load rate increased and the flame temperature increased, the concentrations of NOx grew. The change in the NOx concentrations depended on the change in the oxygen concentrations when the load rate was fixed, and it was observed to be within $30 \%$ in this study. Even in the case of the $100 \%$ load rate when the largest amount of NOx was generated, the values were 75 ppm or lower across the entire section. Particle analyses showed that the generation characteristics (Fig. 7(c)) were similar to those of CO (Fig. 7(a)) in relation to the stability of flame. As to the smoke scale, the allowable standard for combustion of heavy oil is 4 or lower, and though the system developed in this study had values of 2 or lower when the load rate was $80 \%$ or $100 \%$ and the oxygen 
concentration was $7 \%$ or higher, the system will need to be optimized by taking into account the efficiency of the boiler and the characteristics of the exhaust gas as the efficiency of the boiler drops if excess oxygen concentrations increase.

Table 3: Air pollutants analysis.

\begin{tabular}{|l|l|l|}
\hline Component & Concentration & Regulation \\
\hline $\mathrm{HCl}(\mathrm{ppm})$ & 1.85 & $\leq 50$ \\
\hline Dust $\left(\mathrm{mg} / \mathrm{Nm}^{3}\right)$ & 21.455 & $\leq 100$ \\
\hline Dioxin $\left(\mathrm{mg} / \mathrm{Nm}^{3}\right)$ & 0.233 & --- \\
\hline $\mathrm{Cd}\left(\mathrm{mg} / \mathrm{Nm}^{3}\right)$ & 0.016 & $\leq 0.2$ \\
\hline $\mathrm{Zn}\left(\mathrm{mg} / \mathrm{Nm}^{3}\right)$ & 0.720 & $\leq 10$ \\
\hline $\mathrm{Cu}\left(\mathrm{mg} / \mathrm{Nm}^{3}\right)$ & 0.102 & $\leq 10$ \\
\hline $\mathrm{Cr}\left(\mathrm{mg} / \mathrm{Nm}^{3}\right)$ & 0.003 & $\leq 0.5$ \\
\hline $\mathrm{Pb}\left(\mathrm{mg} / \mathrm{Nm}^{3}\right)$ & 0.451 & $\leq 5$ \\
\hline $\mathrm{As}\left(\mathrm{mg} / \mathrm{Nm}^{3}\right)$ & $\mathrm{ND}$ & $\leq 0.5$ \\
\hline
\end{tabular}

When waste plastics are burnt, the exhaust gas may include heavy metals or dioxin. The heavy metal and dioxin results for samples collected in this study are shown in Table 3, along with data for hydrogen chloride and dust. The various heavy metal and dust data showed values far below the allowable emission standards. In the case of dioxin, no allowable standard has been established at present for boilers so we could not obtain comparative data. However, for industrial furnaces, $1 \mathrm{ng} / \mathrm{Nm}^{3}$ of dioxin emissions are allowed for continuous operation and up to $5 \mathrm{ng} / \mathrm{Nm}^{3}$ are allowed for intermittent operations. The system developed in this study, which had no separate removal device installed, showed a value of $0.233 \mathrm{~g} / \mathrm{Nm}^{3}$ for dioxin; thus, it meets the standards for industrial furnaces.

\section{Conclusion}

In this study, the melting/gasification characteristics of polyethylene and polypropylene based plastic pellets were analyzed, and based on the data obtained, a combustion system that uses waste plastic pellets as fuel was developed; its performance was evaluated and the following conclusions were drawn:

(1) The LDPE and PP pellets go through the process of being melted down into elliptical shapes during the melting/gasification process irrespective of whether ignition takes place or not.

(2) Though predictions based on the thermal equilibrium were quite accurate during the initial stage of melting, or if the size of the specimen was small, melting took place faster than predicted at the later stages likely because multiple thermal processes were involved in the melting as the melting advanced.

(3) We have developed a combustor in which waste plastics in the solid state can be fully burnt by going through the processes of thermal decomposition and gasification inside the combustor, and we confirmed that normal operations of the combustor when installed on a boiler system satisfy exhaust gas control standards under the conditions of combustion loads between $45 \%$ and $100 \%$ and oxygen concentrations between $3 \%$ and $15 \%$.

\section{References}

[1] Ministry of Environment Korea, "Environment Statistics Yearbook," pp. 133-151. 2005/2006.

[2] T. Panagiotou and Y. Levendis, "A study on the combustion characteristics of PVC, poly(styrene), poly(ethylene) and poly(propylene) under high heating rates," Combustion and Flame, vol. 99, pp. 53-74, 1994.

[3] Korea Institute of Energy Research, "A study on the development of high-efficiency combustion boiler for RDF," KIER Report A24509, 2002.

[4] F. P. Incropera and D. P. DeWitt, Introduction to Heat Transfer, 3rd Ed. John Wiley \& Sons Inc., p. 349, 1996. 